\title{
Thermal Stability of Co-Fe and Cu Multilayered Thin Films
}

\author{
Peter F. Ladwig, ${ }^{*}$ Jesse D. Olson, ${ }^{*}$ Joseph H. Bunton, ${ }^{* *}$ David J. Larson, ${ }^{* * *}$ Martin C. \\ Bonsager, ${ }^{* * *}$ Robert M. Ulfig, ${ }^{* *}$ Richard L. Martens, ${ }^{* *}$ Y. Austin Chang, ${ }^{* *}$ Edward \\ Oltman, ${ }^{* *}$ Tye T. Gribb, ${ }^{* *}$ Thomas F. Kelly, ${ }^{* *}$ Allan E. Schultz*** and Bharat B. \\ Pant*** \\ *Materials Science Program, University of Wisconsin-Madison, 1509 University \\ Avenue, Madison, WI 53706 \\ ** Imago Scientific Instruments Corporation, 6300 Enterprise Lane, Madison, WI 53719 \\ *** Recording Head Operations, Seagate Technology, 7801 Computer Avenue, \\ Bloomington, MN 55435
}

Intermixing in sputter deposited $\mathrm{Co}-\mathrm{Fe}$ and $\mathrm{Cu}$ thin film multilayers is both of scientific interest and technological importance. Due to their near complete immiscibility in bulk form, the formation of intermixed multilayers seemingly presents a thermodynamic paradox. Furthermore, due to the use of $\mathrm{Co}-\mathrm{Fe}$ and $\mathrm{Cu}$ thin films in the magnetic storage industry, there is interest in associating the degradation in giant magnetoresistive sensor performance with atomic migration in these layers. We have studied $\mathrm{Co}-\mathrm{Fe}$ (Co with a few atomic percent $\mathrm{Fe}$ ) and $\mathrm{Cu}$ multilayers, each layer of $2.5 \mathrm{~nm}$ thickness, in asdeposited and several annealed conditions with TEM, X-ray diffraction, differential scanning calorimetry (DSC), and three dimensional atom probe (3DAP).

The as-deposited condition, Fig. 1(a), shows $\mathrm{Co}-\mathrm{Fe}$ and $\mathrm{Cu}$ layers of relatively high purity. A 28 day anneal at $310^{\circ} \mathrm{C}$, Fig. 1(b), shows drastic changes in multilayer morphology, where a large cluster of $\mathrm{Cu}$ has grown to the point at which it now crosses at least three Co-Fe layers. The multilayer structure is still intact to the right, where it is observed that the $\mathrm{Cu}$ layers are thinner due to the migration of $\mathrm{Cu}$ atoms toward the growing $\mathrm{Cu}$ particle. This multilayer breakdown is in accord with thermodynamic predictions that suggest the multilayer structure forces significant contact between $\mathrm{Co}-\mathrm{Fe}$ and $\mathrm{Cu}$ at the interfaces, whose free energy can be reduced by breaking up into a twophase mixture of $\mathrm{Co}-\mathrm{Fe}$ and $\mathrm{Cu}$ particles. Monte Carlo simulations predict that the breakup of $\mathrm{Co} / \mathrm{Cu}$ multilayers into a two-phase structure is initiated by grain boundary grooving [1].

However, after annealing at $410^{\circ} \mathrm{C}$ for only 5 minutes, Fig. 1(c), a partially intermixed state is observed (coexisting with the clustering at grain boundaries), which appears to be in stark contrast to the immiscibility shown in bulk $\mathrm{Co}-\mathrm{Cu}$ and $\mathrm{Fe}-\mathrm{Cu}$ phase diagrams. DSC results also show evidence of the intermixing in the form of an endothermic heat pulse around $400{ }^{\circ} \mathrm{C}$. Furthermore, theoretical thin film calculations, which include interfacial and strain energy, suggest that at $400^{\circ} \mathrm{C}$ the components of the overall free energy which contribute to intermixing are approximately equal in magnitude to the components which contribute to phase separation. Therefore, it may be possible for the system to evoke a lattice diffusion mechanism at higher temperatures, in addition to the grain boundary mechanism active at lower temperatures, which is fueled by entropy and the heat release provided by the destruction of interface and lattice strain. X-ray 
diffraction results show that this intermixed state is only temporary as the grain boundary clustering mechanism eventually predominates, forming the equilibrium two-phase mixture.
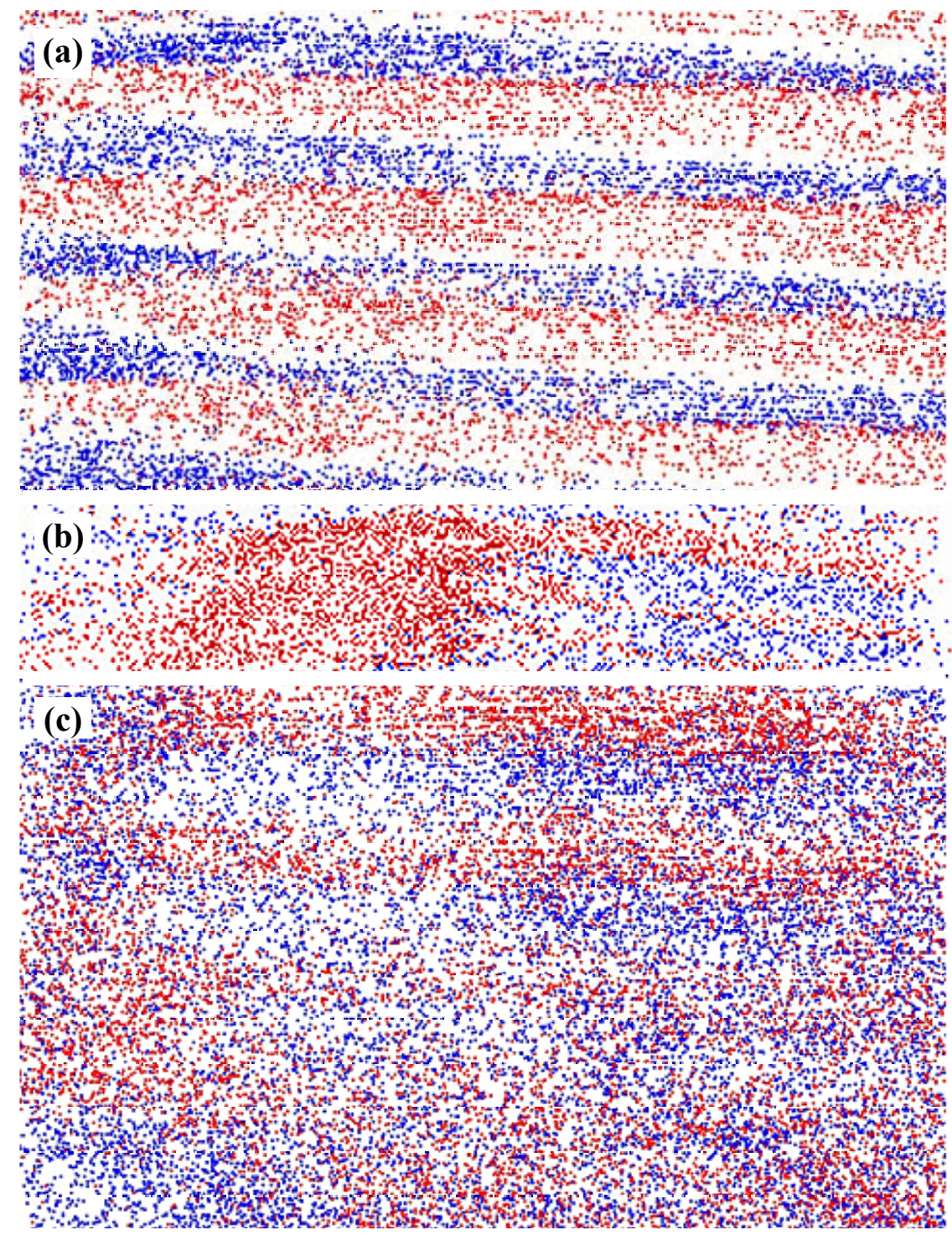

FIG. 1. 2-D cross-section cuts through atom probe datasets. (a) as-deposited. (b) after 310 ${ }^{\circ} \mathrm{C}, 28$ day anneal (shown in lower magnification). (c) after $410{ }^{\circ} \mathrm{C}, 5 \mathrm{~min}$ anneal. $\mathrm{Co}-\mathrm{Fe}$ in blue, $\mathrm{Cu}$ in red.

[1] M. Bobeth, et. al., Z. Metallkd. 92 (2001) 7.

[2]The authors wish to thank Imago Scientific Instruments for the use of the $\alpha$-LEAP atom probe. This research was supported by a grant from Seagate Technology and the Division of Materials Sciences, Office of Basic Energy Research of DOE through grant no. DE-FG02-99ER45777. 